\title{
Ideophones and reduplication
}

\section{Depiction, description, and the interpretation of repeated talk in discourse}

\author{
Mark Dingemanse \\ Max Planck Institute for Psycholinguistics, Nijmegen
}

\begin{abstract}
Repetition is one of the most basic operations on talk, often discussed for its iconic meanings. Ideophones are marked words that depict sensory imagery, often identified by their reduplicated forms. Yet not all reduplication is iconic, and not all ideophones are reduplicated. This paper discusses the semantics and pragmatics of repeated talk with special reference to ideophones. To understand these phenomena, it is useful to distinguish two modes of representation in language - description and depiction - along with cues like prosodic foregrounding that help steer listener's interpretations from one to the other. Reduplication can partake in both modes, which is why it is common in ideophones and other areas of grammar. Using evidence from a range of languages, this paper shows how the study of ideophones sheds light on the interpretation of repeated talk, and argues that both description and depiction are fundamental to understanding how language works.
\end{abstract}

Keywords: ideophones, reduplication, repetition, depiction, iconicity, semantics, pragmatics

\section{Introduction}

Repetition is one of the most basic operations on talk, often discussed for its iconic and expressive meanings. Ideophones are words that are frequently reduplicated. This paper discusses the semantics and pragmatics of repeated talk, with special focus on reduplication and ideophones. It has two aims: first, to investigate some of the factors at play in the interpretation of repeated talk in grammar and discourse; and second, to shed light on how ideophones work and why they are so often reduplicated. The primary data in this paper come from Siwu, a Ghanaian language rich in ideophones and reduplicative processes. The arguments are supported by data from a wide range of other languages, from Korean to Emai and from Japanese to Semai. 
Why ideophones? In a recent volume on total reduplication, we find the following description of the state of the art: "Every once in a while, reduplication researchers feel impelled to mention a special class of words which outwardly are suspiciously reduplicative. Most authors however exclude these elements from their further theorising. This class of words is now commonly known as the class of ideophones" (Stolz, Stroh \& Urdze 2011:64). One goal of this paper is to show what we can learn when we include these elements in our theorising. By looking at repeated talk in everyday discourse, and by comparing ordinary words with ideophones, we learn a number of basic things about the semantics and pragmatics of repetition and reduplication. Of necessity, this will take us somewhat further afield than just the matter of total reduplication, but the journey should be worth it.

Ideophones are words like sinisini 'woven tightly', kpotsro-kpotsro 'moving like a tortoise' and fututuu 'purely white' in Siwu, or tuyjil-tuyjil 'continously floating,' ulakpulak 'unbalanced and scary appearance' and palt'ak 'palpitating, jerking' in Korean (Dingemanse 2012). These vivid sensory words have forms that appear suggestive of their meanings, and an important part of their reputation as iconic words is due to the fact that in actual use, they are more like poetic performances than prosaic descriptions. Ideophones are common among the world's languages; indeed there are many languages in which the lexical class of ideophones appears to be of the same order of magnitude as better studied classes like nouns and verbs (Samarin 1965; Diffloth 1976; Matisoff 2003). They often show reduplication, though this is neither a necessary nor a sufficient feature.

Ideophones have sometimes been excluded from reduplication studies on the assumption that they do not show real reduplication but only meaningless iteration, or alternatively, that the reduplication they show is frozen rather than productive (Stolz, Stroh \& Urdze 2011; Schwaiger 2013). This paper argues that such views need to be amended in the light of empirical cross-linguistic data. Ideophones are one of the primary places where we can observe the role of repeated talk in language use, and reduplication studies have much to gain from a better understanding of ideophones.

\section{A puzzle}

A common topic in this field is the distinction between reduplication as a regular morphological process, and repetition as a syntactic or discourse phenomenon (Gil 2005). Some work has focused on defining the boundary between these phenomena (Thun 1963; Hurch et al. 2008), while other work has argued that they represent the extremes of a continuum moving from iconic, free repetition to arbitrary, bounded reduplication (Wang 2005; Gómez 2009). It is clear that there may be a 
continuum from repetition to reduplication, and that it can be useful to be able to distinguish more grammatical from more expressive processes. What is less clear is when and why a given instance of repeated talk (or replication, the label I shall sometimes use here as an agnostic cover term) could count as one or the other.

What are the cues guiding the interpretation of repeated talk in discourse? In framing the puzzle this way, I mean to highlight the role of speakers and listeners in actual communicative situations. The question of how a given stretch of repeated talk is to be interpreted is not merely a preoccupation for the analyst: it is a question for speakers as they plan and produce speech, and for listeners as they perceive and process it in real time. Solving this puzzle is beyond the scope of a single paper. The aim here is to supply a number of missing pieces: analytic tools that help us make better sense of what is going on.

Consider the following examples of repeated talk from a corpus of naturally occurring conversations in Siwu. They include performance features like hesitations, pauses, and intonational foregrounding (marked with $\uparrow$ ), which I regard not as imperfections but as integral elements of the joint process of sense-making that is conversation (Goodwin 1981; Clark 1996). Example (1) describes the actions of someone manufacturing gunpowder, (2) is a riddle told in conversation, (3) is a description of a handwoven basket, and (4) is a personal story about food preparation.

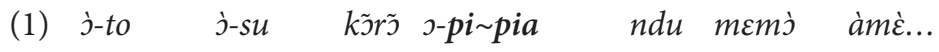
3SG-prog 3SG-take hand 3SG-PLUR put water AGR.DEM inside 'He's dipping his hand repeatedly in the water ...'

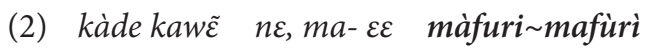

land certain TP ma- HES PL.albino DISTRIB

'There is a land, a- uhm albinos here and there' [riddle]

(3) i matã so

(.) $\uparrow$ sinisini sinisini $\uparrow$

it cling.together self IDPH.woven.tightly $\sim \mathrm{EM} 2$

'It clings together (.) sinisinisinisini!'

(4) ìno lowète $(0.2) \uparrow k p \jmath \uparrow(0.9) \uparrow k p \jmath \uparrow$

1SG-PROG 1sg-pound IDPH.impact IDPH.impact

' $\{$ so\} I'm pounding, (0.2) $k p p s \uparrow(0.9) \uparrow k p s \uparrow$ '

All four examples involve some replication. In Example (1), the verb pia 'put' is partially reduplicated to form the pluractional form pipia 'put repeatedly'. The other three examples feature the replication of a full word. Example (2) illustrates full replication of the noun máfuri 'albino', with a distributive meaning: "albinos here and there" (the answer to the riddle is abialai, a shrub dotted with edible white berries). Example (3) involves the ideophone sinisini 'woven tightly' in reduplicated 
form. Ideophones are often reduplicated quite freely like this. Example (4) involves full repetition of the ideophone $k p$ s 'sound of physical impact. The timing of the repeated material here is quite precise, something we come back to below.

Together, these examples raise a number of questions. Do we want to say there are distinct reduplication processes here or just one, and on what basis are we to make this choice? Are these processes or constructions interpreted in similar ways, and if not, what are some of the cues determining their interpretation? What are the kinds of meanings ascribed to these forms of repeated talk, and how do they relate to each other?

Some of these questions can be answered by means of morphosyntactic analysis. This reveals a number of grammatical and morphological constraints that help us distinguish types of reduplication. The partial reduplication process of (1), for instance, accepts only verbs as input ( ${ }^{*}$ mà màfuri, ${ }^{*}$ si sinisini) and its output is always prefixal reduplication of the first syllable (pi pia from pia 'put', fo fore from fore 'pour', $s a \sim s a$ from $s a$ 'pour'). The distributive full reduplication of (2) accepts only nouns as input $\left({ }^{*}\right.$ pia pia, ${ }^{*}$ sinisini $\sim$ sinisini) and its output is always limited to one copy ( ${ }^{\star}$ màfuri màfuri màfuri). The expressive reduplication of (3) accepts only ideophones as input ( ${ }^{\star}$ pia pia, ${ }^{*}$ màfuri màfuri,), and its output has no preset upper bound (sinisini sinisinisini, etc.), a familiar fact of expressive morphology in ideophones. The performative iteration of (4) accepts ideophones as input ( ${ }^{\star}$ pia pia, ${ }^{\star}$ màfuri màfuri), and its output consists of at least one copy, again without a pre-set upper bound. The main difference between the latter two examples is reduplication versus repetition (Gil 2005). The glosses 'intensification' and 'iteration' are poor representations of their meaning, and will be given more content later as we touch on questions of meaning and mode of representation. Table 1 summarises the properties of these four types of repeated talk.

Table 1. Four types of repeated talk in Siwu and some of their features

\begin{tabular}{llll}
\hline Example & Meaning & Input (category) & Output (replicant) \\
\hline pi pia & pluractional & verbs & one syllable \\
màfuri màfuri & distributive & nouns & exactly one word \\
sinisini sinisini & intensification & ideophones & at least one word \\
$k p$ kpo & iteration & ideophones & at least one word \\
\hline
\end{tabular}

However, there is a sense in which this analytical take remains too far away from the actual facts of language usage. The task of the language scientist is not just to shelve away the types of replication illustrated in a handful of example sentences; it is also to understand how people manage to produce and interpret actual instances of repeated talk in conversation. What are the cues and conceptual tools that enable them to do this? My aim in this paper is to put forward a number of 
notions, drawn from across various disciplines, that are indispensable to the interpretation of repeated talk. First, a distinction is made between description and depiction. This refers to two ways of communicating something: by describing it (propositionally, with words and sentences), or by depicting it (iconically, with sounds and images). As we will see, replication naturally lends itself to the depictive use of speech (iconically suggesting meanings in the domain of repetition, iteration, and distribution), but it is by no means limited to it - which explains why it is so common in ideophones as well as in other areas of grammar. Second, there are the notions of foregrounding and framing. I argue that foregrounding can serve to frame a given stretch of speech as a depiction, distinguishing it from the surrounding descriptive material. Let us explore these conceptual tools a bit further.

\section{Words and images}

In 1929, the surrealist artist Magritte produced one of his best known paintings. Known popularly as "Ceci n'est pas une pipe" after the text on the painting, the actual title is La trahison des images or "The treachery of images". In his work, Magritte problematises the relationship between images and what they represent: after all, nobody can stuff that pipe with tobacco and smoke it. Yet there is another duplicitous aspect to the painting: it contains not one but two representations of a pipe. The first is the image. The second is the word "pipe". The difference between these two is the difference between depiction and description - two distinct modes of representation (Goodman 1968).

\subsection{Depiction and description}

Depictions are typically iconic, representing what they stand for in terms of structural, resemblances between form and meaning. They use material gradiently so that certain changes in form imply analogical differences in meaning. Consider the varying intensity of the strokes of paint that represent the shimmer and shadows on Magritte's pipe, or the continuous movement of a hand gesture mimicking the trajectory of a ball. To interpret depictions, we imagine what it is like to see the thing depicted.

Descriptions are typically arbitrary, without a motivated link between form and meaning. They encode meaning using strings of symbols with conventional significations, as the letters in the word "pipe" or the words in a sentence like "the ball flew over the goal". These symbols are discrete rather than gradient: small differences in form do not correspond to analogical differences in meaning. To 
interpret descriptions, we decode such strings of symbols according to a system of conventions (Table 2).

Table 2. Two modes of signification and their prototypical features

\begin{tabular}{lll}
\hline & Depiction & Description \\
\hline Form-meaning mapping & iconic & arbitrary \\
Building blocks & gradient markings & discrete symbols \\
Interpretation & imagine to interpret & decode to interpret \\
\hline
\end{tabular}

(based on Goodman 1968; Kosslyn 1980; Clark \& Gerrig 1990)

Worrying about the distinction between depiction and description is usually the province of art historians and philosophers (Gombrich 2002; Goodman 1968; Walton 1973). Why should linguists care? Another aspect of Magritte's work provides a clue. In the same year that he produced his famous painting, he also published in a surrealist journal on the relation between word and image (Magritte 1929). Fittingly, the article itself is a hybrid of words and images, with 18 panels presenting aphorisms and illustrations of the many possible relations between words and images. Two of the panels are shown in Figure 1.

Panel 1A presents a written sentence where the main argument of the verb is replaced by an image of the sun: an image incorporated into a sentence. In Panel $1 \mathrm{~B}$, a line appears to form some letters, then a face, again some letters, and then a box. Although it is made in one piece, and built of the same material (ink on paper), we do not interpret all of it in the same way: part is description, part depiction, and somehow we can see what is what.

Une image peut prendre la place d'un mot dans une proposition :

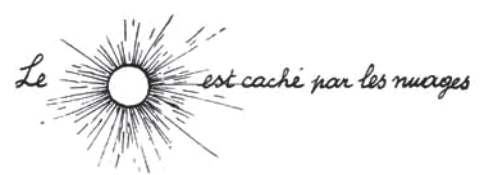

Dans un tableau, les mots sont de la même substance que les images :

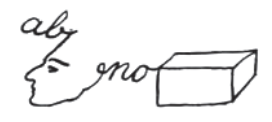

Figure 1. Two panels from Magritte's Les mots et les images (1929).

A: "An image can take the place of a word in a proposition"

B: "In a panel, words can be of the same material as images"

Magritte's aphorisms may seem somewhat flippant until we realise that they also hold for language. More often than not, our utterances in face-to-face interaction are hybrids of word and image. The best known examples of this involve combinations of speech and gesture (Slama-Cazacu 1976; Kendon 1980), but within the vocal channel we also find ample examples. Consider quotations: they are often embedded in our utterances, and yet they are at the same time images - depictive reproductions - of other utterances, produced in such a way as to enable the 
listener to imagine what it is like to experience the thing depicted (Clark \& Gerrig 1990). Or consider ideophones: words like Siwu sinisini 'woven tightly' or $k p$ o 'sound of impact' that depict sensory events by means of iconic mappings between form and meaning. They, too, are a part of our utterances and yet they appear to be more iconic and more gradient - in short, more image-like - than the surrounding words (Diffloth 1980; Dingemanse 2012).

Although it is hard to escape visual metaphors in talking about iconicity (Sonesson 1997), comparing ideophones to images is not entirely satisfactory. After all, images are static and flat representations while ideophones unfold over time and have a rich internal structure in the form of articulatory gestures, prosody, and intonation contours. One way to save the analogy is to see ideophones as moving images. This is the approach taken by Janis Nuckolls, who likens ideophones to cinematic renderings and describes how they may provide close-up shots, wide-angle shots, and time-lapsed sequences of sensory imagery (Nuckolls 1995). Along the same lines, ideophones have been called vocal gestures, drawing attention to their dynamic, free-flowing, gesture-like nature, and to the fact that they often are produced as multi-modal performances (Kunene 2001; McGregor 2001; Dingemanse 2013). We can further emphasize the performance-like aspect of ideophones by characterising them as enactments, a term used in recent work on sign language for what is essentially the same phenomenon (Hodge \& Ferrara 2014; Hodge \& Johnston 2014). Of course, no analogy should be pressed too hard. Whatever the model, the key point about ideophones - and this is what the parallel with Magritte's 'image' is meant to foreground - is that they represent a use of speech that invites and affords the making of iconic mappings between form and meaning.

The iconic mappings of ideophones may involve the imitation of sound with sound (Peirce's imagic iconicity), but often they involve more complex analogies that can be summarised under the term diagrammatic iconicity, where structural relations and modifications in one domain have analogical correspondences in another domain. The verbal material that ideophones are made of has rich internal structure and can vary along a number of continuous dimensions (including pitch, duration, speech rate, loudness, and a myriad of continuously variable articulatory gestures). All of these aspects are available in principle as affordances for iconic mappings. For instance, syllable shapes, vowel length, vowel quality, reduplication, and intonation contours can represent aspectual meanings like event closure, duration, irregularity, iterativity, and telicity - cross-linguistically recurring iconic mappings in ideophones that have been explored in considerable detail by various authors (Westermann 1927; Nuckolls 1996; Hamano 1998; Dingemanse 2012).

The depictive use of speech is not limited to ideophones, as shown by examples like English "a huuuuuge fish", illustrating a phenomenon known as "grading" 
(Bolinger 1961) or "analog acoustic expression" (Shintel, Nusbaum \& Okrent 2006). Yet evidence from a wide range of languages suggests that ideophones have special licence to perform in the depictive mode (Zwicky \& Pullum 1987; Kunene 2001), which even extends to creative forms (Dingemanse 2014). In this sense, ideophones represent a different use of verbal material than ordinary words, just as Magritte's images illustrate a different use of ink than his words.

\subsection{Framing and foregrounding}

Made of speech and produced together with ordinary words, ideophones are a good illustration of Magritte's second aphorism: images and words can be of the same substance. If descriptions and depictions may indeed be combined into one and the same speech signal, this raises a problem that we may call Magritte's question (5):

\section{(5) Magritte's question}

Given that depictions can be combined with descriptions, and given that they can be of the same material, how do we distinguish and interpret them?

Magritte's question is in essence a more general formulation of the puzzle we started out with: how, given a stretch of repeated talk, can we decide how to interpret it? The distinction between description and depiction gives us two interpretive options, but it does not tell us how to decide between them. For this we need a second set of analytic notions: framing and foregrounding.

In panel 1B, Magritte plays a clever trick: parts of a line appear to form letters ("ab", "no") while others appear to form images (a face, an oblong solid), and there is no clear distinction between the two. The effect is reminiscent of the Necker cube illusion, where there is ambiguity as to which side of the cube is facing the viewer, and the viewer can flip between interpretations. In this case, the two interpretations that we can flip between are description and depiction, or word and image. Committing to the 'word' interpretation, we see the beginning and middle parts of an alphabet, and we might scrutinise the surrounding scribbles in search of the missing parts. Committing to the 'image' interpretation, we see a face and a box, and we may wonder what to make of the scribbles attached to them. Somewhat different from a true Necker cube illusion, we are able to see Magritte's line as a strange hybrid combining word and image at once.

Perfectly ambiguous Necker cube effects are quite rare in real life. The original Necker cube illusion is a wireframe illustration that relies on the absence of lighting and perspective - the kinds of cues that we normally use to decide how to interpret what we perceive (Casati 2006). In a similar vein, Magritte has carefully omitted some of the cues that normally help us to distinguish description 
from depiction. One of these cues is framing. The paintings on our walls and the pictures on our pages tend to be framed: set apart from the surrounding material, they invite us to take a particular interpretive stance - to imagine what it is like to experience the thing depicted. As Bateson remarked, "The picture frame tells the viewer that he is not to use the same sort of thinking in interpreting the picture that he might use in interpreting the wallpaper" (Bateson 1955: 187).

There is a clear analogue for this kind of framing in speech: foregrounding. The notion of foregrounding has its origins in the structural linguistics of the Prague School, where Havránek defined it as "the use of the devices of language in such a way that this use itself attracts attention" (Havránek 1964:10). Foregrounding can be achieved by a range of means, from lexical choice to prosody, and it may be used for various ends, from achieving poetic effect (Jakobson 1960) to indicating noteworthiness (Gussenhoven 2004) to signalling a performance (Nuckolls 1996). In all cases, it achieves its effect by virtue of its noticeable difference from what Havránek called the "automatised" language of ordinary sentences. In terms of neo-Gricean pragmatics, the effect is due to an implicature arising from Levinson's M-heuristic (based on Grice's maxim of Manner): "What's said in an abnormal way, isn't normal" (Levinson 2000:38).

So foregrounding signals there is something out of the ordinary. It has long been known that ideophones are a common locus of foregrounding in language use: across languages, people tend to produce them as performances, setting them off from the rest of the utterance by intonational breaks and pitch excursions (Kunene 1965; Childs 1994; Nuckolls 1996). This kind of prosodic foregrounding is one of the cues that make ideophones stand out as noticeably different: framed as depictions amidst otherwise descriptive material.

\subsection{A simple heuristic for interpreting repeated talk}

With these tools in hand, let us return to the first four examples to appreciate an important difference in the way the repeated material is presented. The first set of two appears to be just normal: the repeated talk is well-integrated into the sentence and part of the same intonational unit. The second set is different: there is foregrounding in the form of markedly higher intonation, and brief breaks set off the repeated talk from the rest of the utterance. The effect is that, in the latter two examples, some of the material is framed as distinct from the rest.

With regard to the question of how we interpret repeated talk, we can think of the listener as applying a simple heuristic. If the repeated talk is business as usual, well integrated into an utterance, then it is treated as a description. If the repeated talk is marked, or foregrounded as a performance, then it is treated as a depiction. So framing by means of foregrounding can point the listener towards a type of 
interpretation. Heuristics such as this one play an important role in language processing (Levinson 1995; Hutchinson \& Gigerenzer 2005), as they enable the rapid comprehension that is critical in the realtime flow of conversation.

We can use this heuristic to elucidate the diagnostics for distinguishing reduplication and repetition. According to Gil, one diagnostic of repetition is that the interpretation of repeated talk can be 'iconic or absent' (Gil 2005:33), a disjunction that rather begs the question. The account proposed here helps to explain the equivocation: in the depictive mode, repetition tends to invite iconic interpretations; in the descriptive mode, this is not necessarily the case. The distinction between description and depiction is thus orthogonal to that between reduplication and repetition. The first is a semiotic distinction between two ways in which signs can stand for something, while the second is a linguistic distinction between two ways in which verbal material can be iterated.

If prosody and delivery are informative about the mode of representation we find ourselves in, this should be reflected in the way we represent our data. The pared-down renditions given in Table 1 abstracted away from crucial information. Reinstating it gives us a more accurate view of the four reduplicative processes we started out with. In the leftmost column of Table 3, the special delivery of the examples is now transcribed as in the original transcripts (examples 3 and 4): intonational foregrounding is marked with an upward arrow "个", and aspects of timing are also included. This makes visible the difference between the two sets of examples.

Table 3. Four types of repeated talk in Siwu and their mode of representation

\begin{tabular}{|c|c|c|c|c|}
\hline Example & Meaning & Input & Output & Mode of representation \\
\hline pi pia & pluractional & verbs & one syllable & \multirow{2}{*}{ DESCRIPTION } \\
\hline màfuri màfuri & distributive & nouns & exactly one word & \\
\hline$\uparrow \operatorname{sinisini\sim sinisini\uparrow }$ & intensifying & ideophones & at least one word & \multirow{2}{*}{ DEPICTION } \\
\hline$\uparrow k p \jmath \uparrow(0.9) \uparrow k p \jmath \uparrow$ & iterative & ideophones & at least one word & \\
\hline
\end{tabular}

We can label the two sets according to their mode of representation: description for the first, depiction for the second. But the point of this exercise is not just to multiply labels: we want our analytical categories to have empirical bite. The additional purchase we get from the division into description versus depiction as applied to reduplicative processes is that it helps explain systematic differences in terms of meaning and output.

Meaning. The descriptive reduplicative processes have straightforward grammatical interpretations: the recurrence of some action in time or space (pluractional) or the recurrent spatial distribution of things (distributive) (Kouwenberg \& LaCharité 2001). Although often historically relatable to iconic interpretations, 
these meanings are highly conventionalised, in some cases giving rise to lexicalised forms like nyonys 'search' (from nys nys 'look PLURACTIONAL'). In contrast, the precise meanings of the other two types of repeated talk seem harder to pin down, and to characterise them we need gradient concepts like intensity and degree - a direct reflection of the gradient (as opposed to discrete) aspects of the depictive use of speech. The interpretation of additional reduplication (and lengthening) in ideophones appears not so much to be steered by conventions as retrievable by iconic principles. For instance, the slowly-paced repetition of the semelfactive ideophone $k p$ s 'sound of impact' in the fourth example naturally lends itself to an iterative, sequential reading.

Output. One would be hard-pressed to find a descriptive reduplicative process which does not constrain the output in a specific way; indeed the idea of a single copy - a duple - is virtually a defining feature of reduplication (Inkelas \& Zoll 2005; Inkelas 2008). In line with this, pluractional and distributive reduplication in Siwu both have a constrained output of exactly one syllable or one full word. In contrast, expressive and performative reduplication offer more freedom: their output is at least one word but can be much more. This may seem an arbitrary grammatical fact, until we recall that one of the characteristic features of the depictive mode is that it enables gradient manipulations of the speech signal to support iconic interpretations. The fact that expressive and performative reduplication freely exploit the material of speech naturally follows from the status of ideophones as depictions. How radically different this freedom is from the neatly bounded descriptive reduplicative processes is illustrated in Table 4, which lists the actual forms of ideophones attested in a corpus of everyday speech.

Table 4. Some Siwu ideophones as they occur in a corpus of everyday speech

\begin{tabular}{|c|c|}
\hline Ideophone type & Corpus tokens \\
\hline fututuu 'white' & fututuu|fututuu: |fututu-tutututu|fututu-tutututututu \\
\hline gelegele 'shiny' & gelegelegele $\mid$ gelegele-gelegelegelegelegele $\mid$ gelegele-gelegele \\
\hline giligili 'circular' & giligili | gìligilì-giligiligili \\
\hline kananaa 'silent' & kananaa: | kanana-nananana | kanana-nanananana \\
\hline 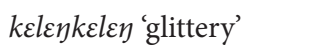 & 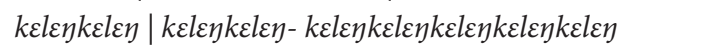 \\
\hline$k p$ s 'sound of impact' & $k p \jmath|k p \jmath, k p \jmath| k p \jmath k p \jmath k_{p o}$ \\
\hline kpinàkpinà 'black' & kpìnàkpìnà | kpìnàkpìnà-kpinàkpinà \\
\hline petspete 'thin and fragile' & 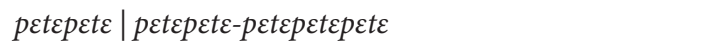 \\
\hline pokıso 'slowly' & 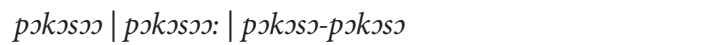 \\
\hline sinisini 'woven tightly' & sinisini $\mid$ sinisini-sinisini $\mid$ sinisini-sinisinisini \\
\hline tsintsin 'neatly' & $t \sin t \sin t \sin t \sin t \sin$ \\
\hline
\end{tabular}


Ideophones sometimes appear in their base form (as in the left column), but their realisation can vary widely on occasions of use. Although speech always allows some degree of prosodic flexibility and no two tokens of words are ever produced in exactly the same way, the degree of expressive freedom shown by ideophones across languages appears to be of a different order altogether. Siwu is not alone in granting the ideophone this kind of expressive freedom; similar findings have been reported for ideophones - but not ordinary words - in Ewe (Ameka 2001), Hixkaryana (Derbyshire 1979), Japanese (Akita 2009), Cha'palaa (Floyd 2012), and Quechua (Nuckolls 1996), among many others. That this difference shows up in the same way across unrelated languages is evidence for the generality of the analysis presented here: recognising two distinct modes of representation helps account for a range of cross-linguistic facts about reduplication and ideophones.

\section{A closer look at reduplication in ideophones}

We have seen that description and depiction are distinct modes of representation with consequences for the interpretation of repeated talk, and that foregrounding can serve as a cue to flip our interpretive stance from description (possibly the default case in spoken language) to depiction. We have also seen that ideophones do not just exhibit frozen reduplication but also undergo additional processes of reduplication in actual discourse. The extravagant freedom displayed by the Siwu ideophones in Table 4 may suggest that reduplication in ideophones is unbounded and irregular, but this is not the case. Depiction, like description, is a systematic mode of representation that is subject to rules and regularities. Though the regularities may be different, they are not absent. ${ }^{1}$

Together with lengthening, the reduplication shown above can be seen as a type of expressive morphology (Zwicky \& Pullum 1987). Though output forms of these expressive morphological processes may vary in length, an important constraint is that the base form of the ideophone is predictive of the kind of expressive morphological processes that may apply to it. To see this, a brief sketch of the morphophonology of ideophones in Siwu is in order. Siwu ideophones come in nine distinct morphophonological templates, six of which feature some form

1. A related point is made by Bergman \& Dahl (1994), who argue, based on evidence from Swedish Sign Language and from ideophones in Kammu (Mon-Khmer), for the existence of three distinct types of reduplication: inflectional, derivational, and ideophonic. Their proposal can be assimilated into the current conceptual framework by linking their ideophonic reduplication' to the depictive mode of representation - with the added benefit of explaining, rather than simply describing, the features of ideophonic reduplication that make it distinct from inflectional and derivational reduplicative processes in other words. 
of inherent ('frozen') reduplication. The templates are listed as numbers 1-9 in Table 5 , and represented in terms of the syllables they are made of. Thus, $\mathbf{A} \cdot \mathbf{B} \cdot \mathbf{A} \cdot \mathbf{B}$ represents a form like sinisini 'woven tightly' and $\mathrm{A} \cdot \mathrm{B} \cdot \mathrm{C}$ represents a triconsonantal form like wùrùfùu 'fluffy'. Together, these 9 templates account for $97 \%$ of the ideophone inventory of Siwu, leaving only a small number of truly exceptional forms like gbrrr 'sensation of electric shock' or korrro karrra 'gnawing through bones' (the repeated /r/ symbolising a geminate trilled [r:]).

Table 5. Types of expressive morphology (EM) in Siwu ideophones

\begin{tabular}{|c|c|c|c|c|c|}
\hline \multicolumn{2}{|r|}{ Template } & & \multirow{2}{*}{$\frac{\mathbf{E M}}{(\mathrm{AB})+}$} & \multirow{2}{*}{$\begin{array}{l}\text { Examples } \\
\text { sinisini sinisinisini }\end{array}$} & \multirow{2}{*}{$\begin{array}{l}{ }^{\star} \text { Ill-formed examples } \\
{ }^{*} \text { sinisini } \sim s i\end{array}$} \\
\hline \multirow{6}{*}{ 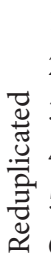 } & $1 \mathrm{~A} \cdot \mathrm{B} \cdot \mathrm{A} \cdot \mathrm{B}$ & & & & \\
\hline & $2 \mathrm{~A} \cdot \mathrm{A}(\cdot \mathrm{A})$ & $9 \%$ & $\cdot A+$ & $S \mathcal{E S E} \sim \mathcal{S E S E S E S E S S E}$ & ${ }^{*} s \varepsilon:$ \\
\hline & $3 A \cdot A \cdot B$ & $9 \%$ & $\cdot \mathrm{A}$ & gbògbòrò gbò & *gbogboro-ro \\
\hline & $4 \mathrm{~A} \cdot \mathrm{B} \cdot \mathrm{B}$ & $8 \%$ & $\cdot \mathrm{B}+$ & fututu tututu & ${ }^{\star} f u t u t u \sim f u,{ }^{\star} f u t u t u \sim f u t u t u$ \\
\hline & $5 \mathrm{~A} \cdot \mathrm{A}: \cdot \mathrm{A}$ & $3 \%$ & $A \cdot A: \cdot A$ & susuusu & ${ }^{*}$ sususususu \\
\hline & $6 \quad A \cdot B \cdot C \cdot A \cdot B \cdot C$ & $2 \%$ & $\cdot(\mathrm{A} \cdot \mathrm{B} \cdot \mathrm{C})+$ & gbadara-gbadara gbadara & ${ }^{*}-r a r a,{ }^{*}-g b a$ \\
\hline \multirow{4}{*}{ 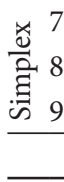 } & $\mathrm{A} \cdot \mathrm{B} \cdot \mathrm{C}:$ & $17 \%$ & $:,(\mathrm{A} \cdot \mathrm{B} \cdot \mathrm{C})+$ & wùrùfùùù, wùrùfù wùrùfù & ${ }^{*}-f \grave{u} f \dot{u},{ }^{*}-w \grave{u}$ \\
\hline & A: & $13 \%$ & : & sùù-ùùùù & *sùùù sùùù \\
\hline & 9 A.B: & $8 \%$ & $:$ & nyàdàà-àààà: & 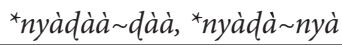 \\
\hline & total & $97 \%$ & & & \\
\hline
\end{tabular}

The templates are specific to ideophones (nouns and verbs tend to have different forms, mostly simpler) so they are a reliable indicator of ideophonehood. This is one of the grounds for noting that reduplication is neither a necessary nor a sufficient criterion for identifying ideophones. Saying that ideophones are reduplicated would account for only 6 out of 9 ideophonic word forms (and only $59 \%$ of ideophones), and would disregard the internal variation even within that subset. Siwu is not unique in showing this diversity of forms in its ideophone inventory; other languages for which sets of morphophonological ideophone templates have been reported include Japanese (Akita 2009), Kisi (Childs 1988), Upper Nexaca Totonac (Beck 2008), Alto Perene Arawak (Mihas 2012), and Japhug (Jacques 2013).

Table 5 shows the nine ideophone templates along with how they can be modified in actual use, making visible some of the regularities underlying the varied examples in Table 4. A colon (“:”) indicates lengthening, while “+” indicates that the number of possible repetitions of this syllable pattern is in principle unlimited, though in practice rarely above 5-7 (due to performance limitations). The types of modification are all but mutually exclusive and they produce output forms that cannot be mistaken for other templates. Most of them specify no upper limit to the number of repetitions or the extent of lengthening. All of them are limited to the domain of ideophones. In other words, we have here a subsystem of expressive 
morphology that is specific to the depictive mode, and that appears to be, as Zwicky \& Pullum have suggested, "in a domain orthogonal to the grammar" (1987:9).

That it may be orthogonal does not, however, imply that it is disorderly. The processes outlined here take specific ideophone templates as input and produce an output that is regular, though not as constrained as ordinary reduplication. Nor does being orthogonal to the grammar (or being in the depictive mode, in terms of the present study) entail having no meaning. The meanings of many of the processes listed in Table 5 lie in domains universally associated with reduplication: plurality, duration, and intensity (Stolz 2007). This is seen most clearly when multiple processes can apply to one ideophone template. Triconsonantal ideophones like wùrùfùù 'fluffy' (template 7) can undergo either expressive lengthening or expressive total reduplication, with concomitant meaning differences as shown in (6):

(6) Expressive morphological processes applying to triconsonantal Siwu ideophones:

wùrùfùu 'fluffy'

safaraa 'rough'

EXPRESSIVE LENGTHENING (intensity):

wùrùfùu $\rightarrow$ wùrù̆fùùùu 'very fluffy'

safaraa $\rightarrow$ safaraaaa 'very rough'

EXPRESSIVE TOTAL REDUPLICATION (distribution in space or time):

wùrùfùù $\rightarrow$ wùrùfù wùrùfù ( wùrùfù...) 'fluffy here and there'

safaraa $\rightarrow$ safara safara( safara...) 'rough here and there'

Some of the reduplicative processes applying to ideophones are quite similar to those applying to ordinary words. The expressive total reduplication in (6), for instance, is similar in meaning to the distributive total reduplication of nouns we saw in example (2) with màfuri mafuri 'albinos here and there'. The main difference is the boundedness of the output: the ideophone may be reduplicated more than once (wùrùfù-wùrùfù-wùrùfù 'fluffy here and there and there, etc.'), whereas nominal total reduplication is always limited to exactly one copy ( ${ }^{*}$ màfuri-mafurimafuri 'albinos here and there, etc.'). Here, then, we see that description and depiction may be distinct, but not strictly isolated: they bleed into each other, and reveal that depictive reduplication of ideophones may be a possible source model for more grammatical forms of reduplication.

Many other languages likewise have regular reduplicative processes that apply to ideophones. In Emai, an Edoid language spoken in Nigeria (Egbokhare 2001), attributive ideophones can undergo optional total reduplication. The process is quite similar to total reduplication in Siwu ideophones in that the long final vowel of the non-reduplicated form is lacking in the reduplicated counterpart. The meaning appears to be one of intensification or iteration. 
(7) Reduplication in Emai ideophones (Edoid, Nigeria) (Egbokhare 2001:89) TOTAL REDUPLICATION (intensification/iteration)

hií 'silence' $\rightarrow$ híhíhí 'eerie'

yúú 'flow' $\rightarrow$ yúyúyú 'gushing'

lógóó 'height' $\rightarrow$ lógólógó 'lanky'

In Semai, an Aslian language of Peninsular Malaysia (Diffloth 1976; Tufvesson 2011), ideophones (usually called 'expressives' in this language family) can undergo a number of morphological processes, three of which are listed in (8). Major reduplication is suffixed reduplication of the major syllable: the whole root for CVC roots like tus 'sound of running fast', or the last syllable for more complex roots like $d y \tilde{z}: l$ 'appearance of an object floating down a river'. Minor reduplication is prefixed reduplication of a minor syllable "made of two consonants identical respectively to the first and last consonants of the root: $C^{\mathrm{i}} \ldots \mathrm{C}^{\mathrm{f}} \rightarrow \mathrm{C}^{\mathrm{i}} \mathrm{C}^{\mathrm{f}}-\mathrm{C}^{\mathrm{i}} \ldots$ $C^{f}$ " (Diffloth 1976:252). Antiphonic reduplication is prefixed reduplication of the whole root, but with modification of the vowel. Each of these processes has a distinct, clearly specified meaning.

(8) Reduplication in Semai ideophones (Aslian, Malaysia) (Diffloth 1976:251-2) MAJOR REDUPLICATION (repetition at intervals of time)

tus $\rightarrow$ tustustus 'repeated sound of running fast'

$d y \tilde{z}: l \quad \rightarrow \quad d y \tilde{z}: l y \tilde{s}: l \quad$ 'appearance of object floating down river and getting stuck here and there' MINOR REDUPLICATION (prolongation or continuation)

$d y \tilde{z}: l \quad \rightarrow \quad d l d y \tilde{:}: l$ 'appearance of object which goes on floating down river' ANTIPHONIC REDUPLICATION (irregularity distributed in time or space) $k l c w \tilde{\varepsilon} c \rightarrow k l c w \tilde{u} c k l c w \tilde{\varepsilon} c$ 'irregular flapping circular movements (e.g., of a tortoise's feet struggling to escape)'

Korean, well known for its extensive ideophone system (Martin 1962; Lee 1992; Sien 1997), has at least two productive reduplicative processes that apply to ideophones: partial reduplication, in which the first CV of a root is prefixed; and total reduplication, in which a whole root is fully reduplicated. The processes have distinct, clearly specified meanings of "attenuation" (intensive reduplication) and "prolongation or continuation" (total reduplication). The derivational nature is shown by the fact that we can even feed one into the other: tutuyjil tutuyjil 'continuously floating very lightly' (Sien 1997:206).

(9) Reduplication in Korean ideophones (Isolate, Korea) (Sien 1997) INTENSIVE REDUPLICATION (attenuation) tuyjil $\rightarrow$ tu tunjil 'lightly floating' TOTAL REDUPLICATION (prolongation or continuation) tuyjil $\rightarrow$ tuyjil tuyjil 'continuously floating' 
In sum, the reduplicative processes we find in ideophones can be regular and productive, and the meanings ascribed to some of them are not very different from the kinds of meanings ascribed to descriptive reduplicative processes. I have given examples from four languages, but many more could be cited; from Yanomami (Gómez 2009) to Chintang (Rai et al. 2005) and from Hausa (Newman 1989) to Cha'palaa (Floyd 2012).

Besides showing the productivity and regularity of reduplicative processes in ideophones, these examples raise the question how the descriptive and depictive modes of representation in general, and reduplicative processes in ideophones and non-ideophones in particular, can be related to each other. For if we learn one thing from the above - from the hybrid word-images of Magritte to the ideophones of Korean - it is that despite fundamental differences, there is no impermeable barrier between description and depiction.

\section{Reduplication can bridge description and depiction}

One reason for the exclusion of ideophones from consideration in reduplication studies has been the assumption that ideophones do not show productive reduplication, at most repetition without a distinctive meaning (Stolz, Stroh \& Urdze 2011:65). The evidence presented here suggests this assumption is not correct. If at least some ideophones in at least some languages show proper reduplication, there is no coherent reason to exclude them from consideration; we would be arbitrarily excising part of the very phenomenon that we are trying to understand.

Another reason for excluding ideophones has been the assumption that they do not involve the reduplication of independently existing simplex forms (Stolz, Stroh \& Urdze 2011; Schwaiger 2013). The idea here seems to be that ideophones are inherently reduplicated, and therefore of less interest to studies of productive processes of reduplication. The evidence presented here raises two problems with these assumptions. First, even ideophones that appear to be inherently reduplicated regularly undergo additional productive reduplicative processes. Second, many languages have substantial numbers of ideophones that are not inherently reduplicated, but can serve as input for processes of repetition and reduplication. In Siwu, as we saw above, 59\% of ideophones have reduplicated base forms (215 out of 364). In Japanese ideophones, the proportion of reduplicated base forms is 35.4\% (584 out of 1652) (Akita 2009; Kadooka 2007 gives 40\%). Only 7\% of the 111 Somali ideophones discussed by Dhoorre \& Tosco (1998) have reduplicated 
base forms. In fact (although actual counts are too rare to be sure) it is hard if not impossible to find a language in which all ideophones are reduplicated. ${ }^{2}$

Two putative reasons for excluding ideophones from consideration in reduplication studies do not hold up to scrutiny. But not only is there a lack of reasons for excluding ideophones, there are important reasons for including them in our view of reduplication and of language more generally. Most importantly, we gain a more complete understanding of repeated talk and the functions to which it is put in natural languages.

Let us return to Siwu for more evidence of the role of reduplication as a bridge between depiction and description, or between ideophones and other types of words. There is a small set of cases of reduplicated ideophones with corresponding unreduplicated words, mostly verbs (10). In all of these cases it is difficult to establish the direction of derivation, although given that monovocal CVCV verb forms are rare in Siwu, one might speculate that at least some of these are derived from ideophones. (A converse case of ideophones derived from verbs has been well described for the Atlantic language Kisi by Childs (1989).)

(10) Verb/ideophone pairs; directionality hard to establish (Siwu)

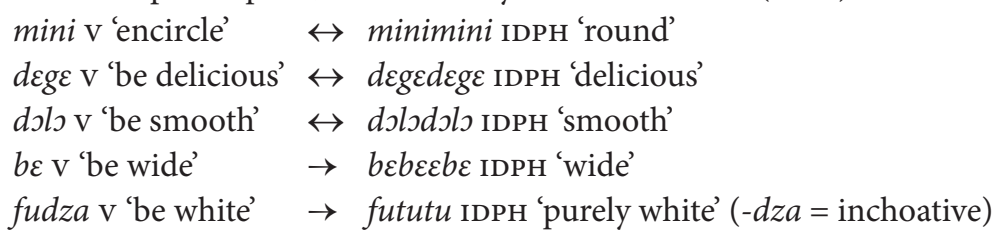

Another set of examples concerns the relation between ideophones and nouns. The full reduplication of some nouns may form ideophones, as shown in (11). In some cases the counterparts are seen as separate words and speakers report being surprised when pointed to the possible relation, as in $\dot{j} m \tilde{\varepsilon} r \tilde{\varepsilon}$ 'sweetness' and its ideophonic counterpart $m \tilde{\varepsilon} r \tilde{\varepsilon} m \tilde{\varepsilon} r \tilde{\varepsilon}$ 'sweet'. In other cases, there is more evidence of productivity. For instance, a beady texture may be described as kùbikubi 'bead', with the reduplication contributing distributive semantics; and something similar

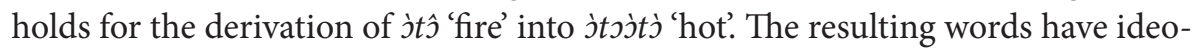
phonic properties - a marked reduplicated form, a meaning in the domain of sensory imagery - but their tone pattern betrays their non-ideophonic origin, as ideophones in Siwu are predominantly monotonal. Such forms may eventually be assimilated into the ideophone inventory.

2. A reviewer points out that these observations can be phrased as a language universal: if a language has non-reduplicated ideophones, it also has reduplicated ideophones. I think this is true, and less trivial than it sounds. After all, the same thing cannot be said for verbs and nouns in every language. The reason it might seem trivial is because ideophones are so clearly depictive, and repetition is so clearly one of the most basic iconic processes one can apply to talk. 
(11) Noun reduplication may form ideophones (Siwu)

jm $\tilde{\varepsilon} r \tilde{\varepsilon} \mathrm{N}$ 'sweetness' $\leftrightarrow m \tilde{\varepsilon} r \tilde{\varepsilon} m \tilde{\varepsilon} r \tilde{\varepsilon}$ IDPH 'sweet'

kùbi $\mathrm{N}$ 'bead' $\rightarrow$ kùbikubi IDPH? 'beady'

itô N 'fire' $\rightarrow$ jtost’̀ IDPH? 'hot'

Nouns may also be derived from ideophones, as in (12), where the addition of the noun class prefix $\mathrm{ka}$ - signifies nominal status. So both directions of derivation are attested in Siwu.

(12) Ideophones may form nouns (Siwu)

fututu IDPH 'white' $\rightarrow$ kàfututu N 'TV'

gbugburu IDPH 'stout' $\rightarrow$ kàgbugburugbu N 'dwarf'

These examples bring into view the fuzzy edges of the category of ideophones in Siwu, and the extent to which word classes spill over into each other. None of this should be surprising to typologists, who are used to seeing similar relations between better studied word classes like nouns, verbs, and adjectives (Dryer 1997; Croft \& van Lier 2012). What it shows is that ideophones, although words of a distinct kind, are not incommensurable with other types of words (Newman 2001). There are productive morphological derivational relations in multiple directions, often involving reduplication or repetition.

Let me bring the argument full circle by returning to the repeated ideophone of one of the first examples, shown below as (13). The repeated talk is set off from the rest by means of a brief pause and intonational foregrounding: hallmarks of depiction (Nuckolls 1996). The utterance, taken from a story told in conversation, features a repeated ideophone $k p$ s 'sound of impact' to depict the act of pounding for food preparation. Within the stretch of depictive speech, the ideophone tokens are separated by a relatively long pause. This makes it possible to understand the example as accomplishing more than mere repetition for intensification: it is rather an accurately timed recreation of the pounding event. That it is quite accurate is anecdotally confirmed by the fact that the speed of pounding in this case marks the speaker as someone "pounding like an elderly lady", as one of my consultants correctly observed on the basis of a reenactment.
(13) ìdo
lowètè
(0.2) $\uparrow k p \jmath \uparrow$
(0.9) $\uparrow k p \jmath \uparrow$
1SG-PROG 1sg-pound
IDPH.impact
IDPH.impact

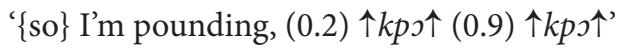

Yet even such exquisitely depictive material can be drawn back into the realms of description. Consider the following example from the corpus. The setting is one in which someone is making gunpowder by assembling ingredients and pounding them. The speaker wants to check his understanding of what is going on: isn't the 
gunpowder being produced for a funeral? (In the Siwu-speaking area, funerals often feature ceremonial gunfire.) He formulates this question as follows:

\section{(14) ide kàku kere tá-màbara kpjkpj̀kpj-j̀? S.I-be funeral just PROG-3PL-do pounding-Q 'Isn't it for a funeral that the kpokpskpo [pounding] is being done?'}

The expression used to refer to the pounding activity is $k p \jmath k p \jmath p$, in which we can recognise the same ideophone as above, $k p$ o 'sound of impact'. Yet the word $k p \jmath k p k p \jmath$ is a deideophonic noun, appearing as the argument of a verb. It is embedded in an interrogative utterance, not normally compatible with ideophones, and it bears conventional polar question marking in the form of final vowel lengthening. There is no foregrounding setting apart the word from the rest of the utterance, and the word is part of the larger intonational phrase, rather than carving out its own intonational contour. The word shows internal reduplication reminiscent of the source ideophone, but the lack of foregrounding and the morphosyntactic embedding suggests that it has been plucked from the depictive mode, as it were, and stuck into the descriptive mode. This is a vivid illustration of the derivational relations that exist between ideophones and other words. It underlines once more that description and depiction are not insulated from each other and are best studied in conjunction.

\section{Conclusion}

In Doppelung (Pott 1862), possibly the first typological study of reduplication, August Friedrich Pott amassed a wealth of data on reduplication and repetition in many of the world's languages. One of the languages he singled out was Yoruba, a Volta-Congo language spoken in present-day Nigeria, "worin die Doppelung eine äußerst mannichfaltige Anwendung findet” (Pott 1862:273). His main interest in Yoruba was a class of adverbs that seemed especially susceptible to various kinds of repetition and reduplication. Today, these adverbs are known as ideophones.

In the one and the half century since Pott, ideophones have often been ignored or excluded from theorising - sometimes by scholars who may be unaware of the prevalence of ideophones in the world's languages (Newmeyer 1992; relying on Whitney 1874), sometimes by experts over-emphasising their exceptional and exotic nature (cf. examples cited in Newman 2001). In this paper I have shown some of the things we gain by including them. Across languages, ideophones are a primary locus of repeated talk, frozen as well as productive. If we want to understand repeated talk in all its aspects, from creative expression to conventionalised 
meaning, from synchrony to diachrony, from lexicon to grammar, from depiction to description, we had better consider all the relevant evidence.

I have shown how the study of ideophones can contribute conceptual tools for general application, such as the distinction between description and depiction, and the processes of foregrounding and framing. I have challenged the idea that reduplication in ideophones is meaningless or unproductive, and I have shown that reduplication in ideophones, though freer than the reduplicative processes normally considered in studies of reduplication, is nonetheless subject to its own rules and regularities. All throughout, these points have been supported by empirical evidence from naturally occurring speech. This allowed us to see how foregrounding works in practice, how seemingly rambling repetition may in fact be related to regular reduplication, and how derivational processes may move in either direction between description and depiction.

One of Dwight Bolinger's metaphors for language runs like this: "Language is digital, not analog: its units function by being either present or absent, not by being present in varying degrees. ... But the digital island floats on an analog sea.... It would not be surprising if now and then a bit of the analog sea washed over the digital island" (Bolinger 1968:17). The metaphor should probably not be pushed too far (is language like the forbidding Rock of Gibraltar or more like the lush Okavango Delta?), but the distinction between digital and analog corresponds to that between description and depiction - and the reason repeated talk is so special is because it can partake in both. One of the best places to observe this dual character, the analog sea washing over the digital shores, is in ideophones. Perhaps by looking at ideophones we get a glimpse of the true hybrid nature of language.

\section{Acknowledgements}

This paper has benefited from comments and questions by Kimi Akita, Daniela Rossi, Philippe de Brabanter, Herb Clark, Simeon Floyd, and three anonymous reviewers for Studies in Language. Portions of this work were adapted and extensively revised from an unpublished $\mathrm{PhD}$ thesis, and the arguments have been refined thanks to audiences at the workshops on Total Reduplication (Brussels 2012), Quotation and Depiction in Interaction (Nijmegen 2013), and Structuring Sensory Imagery (Rochester 2014). The research was funded by the European Research Council Grant 240853 and by an NWO Veni grant. 


\section{References}

Akita, Kimi. 2009. A Grammar of Sound-Symbolic Words in Japanese: Theoretical Approaches to Iconic and Lexical Properties of Japanese Mimetics. Kobe: Kobe University dissertation. http://www.lib.kobe-u.ac.jp/handle_gakui/D1004724.

Ameka, Felix K. 2001. Ideophones and the Nature of the Adjective Word Class in Ewe. In F. K. Erhard Voeltz \& Christa Kilian-Hatz (eds.), Ideophones, 25-48. Amsterdam: John Benjamins. DOI: 10.1075/tsl.44.04ame

Bateson, Gregory. 1955. A theory of play and fantasy. Psychiatric Research Reports 2(39). 39-51. Beck, David. 2008. Ideophones, adverbs, and predicate qualification in Upper Necaxa Totonac. International Journal of American Linguistics 74(1). 1-46. DOI: 10.1086/529462

Bergman, Brita \& Östen Dahl. 1994. Ideophones in Sign Language? The place of reduplication in the tense-aspect system of Swedish Sign Language. In Carl Bache, Hans Basbøll \& Carl-Erik Lindberg (eds.), Tense, aspect and action: Empirical and theoretical contributions to language typology, 397-422. Berlin: Mouton de Gruyter.

Bolinger, Dwight L. 1961. Generality, gradience, and the all-or-none. The Hague: Mouton \& co.

Bolinger, Dwight L. 1968. Aspects of language. New York: Harcourt, Brace and World.

Casati, Roberto. 2006. The cognitive science of holes and cast shadows. Trends in Cognitive Sciences 10(2). 54-55. DOI: 10.1016/j.tics.2005.12.008

Childs, G. Tucker. 1988. The phonology and morphology of Kisi. Berkeley: University of California, Berkeley dissertation.

Childs, G. Tucker. 1989. Where do ideophones come from? Studies in the Linguistic Sciences 19(2). 55-76.

Childs, G. Tucker. 1994. African Ideophones. In Leanne Hinton, Johanna Nichols \& John J. Ohala (eds.), Sound Symbolism,178-204. Cambridge: Cambridge University Press.

Childs, G. Tucker. 2014. Constraints on violating constraints: How languages reconcile the twin dicta of 'Be different' and 'Be recognizably language'. Pragmatics and Society 5(3). 341-354. DOI: $10.1075 / \mathrm{ps} .5 .3 .02 \mathrm{chi}$

Clark, Herbert H. 1996. Using language. Cambridge: Cambridge University Press. DOI: $10.1017 / \mathrm{CBO} 9780511620539$

Clark, Herbert H. \& Richard J. Gerrig. 1990. Quotations as demonstrations. Language 66(4). 764-805. DOI: 10.2307/414729

Croft, William \& Eva van Lier. 2012. Language universals without universal categories. Theoretical Linguistics 38 (1-2).

Derbyshire, Desmond C. 1979. Hixkaryana. Amsterdam: North-Holland Pub. Co.

Dhoorre, Cabdulqaadir Salaad \& Mauro Tosco. 1998. 111 Somali ideophones. Journal of African Cultural Studies 11(2). 125-156. DOI: 10.1080/13696819808717831

Diffloth, Gérard. 1976. Expressives in Semai. Oceanic Linguistics Special Publications 13. 249264.

Diffloth, Gérard. 1980. Expressive phonology and prosaic phonology in Mon-Khmer. In Theraphan L. Thongkum (ed.), Studies in Mon-Khmer and Thai phonology and phonetics in honor of E. Henderson, 49-59. Bangkok: Chulalongkorn University Press.

Dingemanse, Mark. 2012. Advances in the cross-linguistic study of ideophones. Language and Linguistics Compass 6(10). 654-672. DOI: 10.1002/lnc3.361

Dingemanse, Mark. 2013. Ideophones and gesture in everyday speech. Gesture 13(2). 143-165. DOI: 10.1075/gest.13.2.02din 
Dingemanse, Mark. 2014. Making new ideophones in Siwu: A case study of creative depiction. Pragmatics and Society 5(3). 384-405. DOI: 10.1075/ps.5.3.04din

Dryer, Matthew S. 1997. Are grammatical relations universal? In Joan Bybee, John Haiman \& Sandra A. Thompson (eds.), Essays on language function and language type, 115-143. Amsterdam: John Benjamins. DOI: 10.1075/z.82.09dry

Egbokhare, Francis O. 2001. Phonosemantic correspondences in Emai attributive ideophones. In F. K. Erhard Voeltz \& Christa Kilian-Hatz, Ideophones, 87-96. Amsterdam: John Benjamins. DOI: 10.1075/tsl.44.08egb

Floyd, Simeon. 2012. Four types of reduplication in the Cha'palaa language of Ecuador. In Hein van der Voort \& Gale Goodwin Gómez (eds.), Reduplication in South American Indian languages. Leiden: Brill.

Gil, David. 2005. From repetition to reduplication in Riau Indonesian. In Bernhard Hurch \& Veronika Mattes (eds.), Studies on reduplication. Berlin; New York: Mouton de Gruyter.

Gombrich, E. H. 2002. Art \& illusion: A study in the psychology of pictorial representation, 6th edn. London/New York: Phaidon.

Gómez, Gale Goodwin. 2009. Reduplication, ideophones, and onomatopoeic repetition in the Yanomami languages. Grazer Linguistische Studien 71. 21-38.

Goodman, Nelson. 1968. Languages of art: An approach to the theory of symbols. Indianapolis: Bobbs-Merrill.

Goodwin, Charles. 1981. Conversational organization: Interaction between speakers and hearers. New York: Academic Press.

Gussenhoven, Carlos. 2004. The phonology of tone and intonation. Cambridge: Cambridge University Press. DOI: 10.1017/CBO9780511616983

Hamano, Shoko Saito. 1998. The sound-symbolic system of Japanese. Stanford: CSLI.

Havránek, Bohuslav. 1964. The functional differentiation of the standard language. In Paul L. Garvin (ed.), A Prague School reader on esthetics, literary structure, and style, 3-16. Washington: Georgetown University Press.

Hodge, Gabrielle, and Lindsay Ferrara. 2014. "Showing the Story: Enactment as Performance in Auslan Narratives." In L. Gawne and J. Vaughan (eds.), Selected Papers from the 44th Conference of the Australian Linguistic Society, 372-97. Melbourne, Australia. http://minerva-access.unimelb.edu.au/handle/11343/40973.

Hodge, Gabrielle \& Trevor Johnston. 2014. Points, depictions, gestures and enactment: Partly lexical and non-lexical signs as core elements of single clause-like units in Auslan (Australian Sign Language). Australian Journal of Linguistics 34(2). 262-291.

DOI: $10.1080 / 07268602.2014 .887408$

Hurch, B., M. Kajitani, V. Mattes, U. Stangel \& R. Vollmann. 2008. Other reduplication phenomena. http://reduplication.uni-graz.at/texte/Other_Red_Phen.pdf.

Hutchinson, John \& Gerd Gigerenzer. 2005. Simple heuristics and rules of thumb: Where psychologists and behavioural biologists might meet. Behavioural processes 69(2). 97-124. DOI: 10.1016/j.beproc.2005.02.019

Inkelas, Sharon. 2008. The dual theory of reduplication. Linguistics 46(2). 351-401. DOI: $10.1515 /$ LING.2008.013

Inkelas, Sharon \& Cheryl Zoll. 2005. Reduplication: Doubling in morphology. Cambridge: Cambridge University Press. DOI: 10.1017/CBO9780511627712

Jacques, Guillaume. 2013. Ideophones in Japhug Rgyalrong. Anthropological Linguistics 55(3). 256-287. DOI: 10.1353/anl.2013.0014 
Jakobson, Roman. 1960. Linguistics and Poetics. In Thomas A. Sebeok (ed.), Style in Language, 350-377. Cambridge, MA: MIT Press.

Kadooka, Ken-Ichi. 2007. Nihongo onomatope-goi-ni-okeru keitaiteki-on'inteki-taikeisei-ni-tuite [On morphological and phonological systematicity in Japanese onomatopoeic vocabularies]. Tokyo: Kurosio Publishers.

Kendon, Adam. 1980. Gesticulation and speech: Two aspects of the process of utterance. In Mary Ritchie Key (ed.), The relationship of verbal and nonverbal communication, 207-227. The Hague: Mouton.

Kosslyn, Stephen M. 1980. Image and mind. Cambridge, MA: Harvard University Press.

Kouwenberg, Silvia \& Darlene LaCharité. 2001. The iconic interpretations of reduplication: Issues in the study of reduplication in Caribbean Creole languages. European Journal of English Studies 5(1). 59-80. DOI: 10.1076/ejes.5.1.59.4783

Kunene, Daniel P. 1965. The ideophone in Southern Sotho. Journal of African Languages 4. 19-39.

Kunene, Daniel P. 2001. Speaking the act: The ideophone as a linguistic rebel. In F. K. Erhard Voeltz \& Christa Kilian-Hatz (eds.), Ideophones, 183-191. Amsterdam: John Benjamins. DOI: $10.1075 /$ tsl.44.15kun

Lee, Jin-Seong. 1992. Phonology and sound symbolism of Korean ideophones. Indiana University dissertation.

Levinson, Stephen C. 1995. Interactional biases in human thinking. In Esther N. Goody (ed.), Social intelligence and interaction: Expressions and implications of the social bias in human intelligence, 221-260. Cambridge: Cambridge University Press.

DOI: $10.1017 /$ CBO9780511621710.014

Levinson, Stephen C. 2000. Presumptive meanings: The theory of generalized conversational implicature. MIT Press.

Magritte, René. 1929. Les mots et les images. La Révolution surréaliste 12. 32-33.

Martin, Samuel E. 1962. Phonetic symbolism in Korean. In Nicholas Poppe (ed.), American studies in Altaic linguistics, 177-189. Bloomington: Indiana University Publications.

Matisoff, James A. 2003. Aslian: Mon-Khmer of the Malay Peninsula. Mon-Khmer Studies: 1-58.

McGregor, William. 2001. Ideophones as the source of verbs in Northern Australian languages. In F. K. Erhard Voeltz \& Christa Kilian-Hatz (eds.), Ideophones, 205-221. Amsterdam: John Benjamins. DOI: $10.1075 /$ tsl.44.17mcg

Mihas, Elena. 2012. Ideophones in Alto Perene (Arawak) from Eastern Peru. Studies in Language 36(2). 300-344. DOI: 10.1075/sl.36.2.04mih

Newman, Paul. 1989. Reduplication and tone in Hausa ideophones. Proceedings of the Annual Meeting of the Berkeley Linguistics Society 15. 248-255.

Newman, Paul. 2001. Are ideophones really as weird and extra-systematic as linguists make them out to be? In F. K. Erhard Voeltz \& Christa Kilian-Hatz (eds.), Ideophones, 251-258. Amsterdam: John Benjamins. DOI: 10.1075/tsl.44.20new

Newmeyer, Frederick J. 1992. Iconicity and generative grammar. Language 68(4). 756-796. DOI: 10.1353/lan.1992.0047

Nuckolls, Janis B. 1995. Quechua texts of perception. Semiotica 103(1/2). 145-169. DOI: $10.1515 /$ semi.1995.103.1-2.145

Nuckolls, Janis B. 1996. Sounds like life: Sound-symbolic grammar, performance, and cognition in Pastaza Quechua. New York: Oxford University Press.

Pott, August Friedrich. 1862. Doppelung (Reduplikation, Gemination): als eines der wichtigsten Bildungsmittel der Sprache, beleuchtet aus Sprachen aller Welttheile. Lemgo \& Detmold: Meyer. 
Rai, Novel Kishore, Balthasar Bickel, Goma Banjade, Martin Gaenszle, Elena Lieven, Netra Paudyal, Ichchha Rai \& Sabine Stoll. 2005. Triplication and ideophones in Chintang. In Yogendra Yadava, Govinda Bhattarai, Ram Raj Lohani, Balaram Prasain \& Krishna Parajuli (eds.), Contemporary issues in Nepalese linguistics, 205-209. Kathmandu: Linguistic Society of Nepal.

Samarin, William J. 1965. Perspective on African ideophones. African Studies 24(2). 117-121. DOI: $10.1080 / 00020186508707214$

Schwaiger, Thomas. 2013. On the structure of reduplicants: Iconicity and preferred form in reduplication. In Nabil Hathout, Fabio Montermini \& Jess Tseng (eds.), Morphology in Toulouse: Selected Proceedings of Décembrettes 7, 211-229. München: LINCOM Europa.

Shintel, Hadas, Howard C. Nusbaum \& Arika Okrent. 2006. Analog acoustic expression in speech communication. Journal of Memory and Language 55(2). 167-177.

DOI: $10.1016 /$ j.jml.2006.03.002

Sien, Nam-Cheol. 1997. An autosegmental analysis of ideophones in Korean. University of Washington dissertation.

Slama-Cazacu, Tatiana. 1976. Nonverbal components in message sequence:'Mixed syntax'. In W.C. McCormack \& S.A. Wurm (eds.), Language and man: Anthropological issues: 217227. The Hague: Mouton.

Sonesson, Göran. 1997. The ecological foundations of iconicity. In Irmengard Rauch \& Gerald F. Carr (eds.), Semiotics around the world: Synthesis in diversity. Proceedings of the Fifth International Congress of the IASS, Berkeley, June 12-18, 1994, 739-742. Berlin: Mouton de Gruyter.

Stolz, Thomas. 2007. Re: duplication; Iconic vs counter-iconic principles (and their areal correlates). In Paolo Ramat \& E. Roma (eds.), Europe and the Mediterranean as linguistic areas; Convergencies from a historical and typological perspective, 317-350. Amsterdam/ Philadelphia: John Benjamins. DOI: 10.1075/slcs.88.14sto

Stolz, Thomas, Cornelia Stroh \& Aina Urdze. 2011. Total reduplication: The areal linguistics of a potential universal. Oldenbourg: Akademie Verlag. DOI: 10.1524/9783050050973

Thun, Nils. 1963. Reduplicative words in English; a study of formations of the types tick-tick, hurlyburly, and shilly-shally. Uppsala: Carl Bloms Boktryckeri.

Tufvesson, Sylvia. 2011. Analogy-making in the Semai sensory world. The Senses and Society 6(1). 86-95. DOI: 10.2752/174589311X12893982233876

Walton, Kendall L. 1973. Pictures and Make-Believe. The Philosophical Review 82(3). 283-319. DOI: $10.2307 / 2183897$

Wang, Shih-ping. 2005. Corpus-based approaches and discourse analysis in relation to reduplication and repetition. Journal of Pragmatics 37(4). 505-540.

DOI: $10.1016 /$ j.pragma.2004.08.002

Westermann, Diedrich Hermann. 1927. Laut, Ton und Sinn in westafrikanischen Sudansprachen. In Franz Boas (ed.), Festschrift Meinhof, 315-328. Hamburg: L. Friederichsen.

Whitney, William Dwight. 1874. Physei or thesei - natural or conventional? Transactions of the American Philological Association 6. 95-116. DOI: 10.2307/2935821

Zwicky, Arnold M. \& Geoffrey K. Pullum. 1987. Plain morphology and expressive morphology. In John Aske, Beery, Natasha, Laura Michaelis \& Hana Filip (eds.), Proceedings of the Thirteenth Annual Meeting of the Berkeley Linguistics Society, VII:330-340. Berkeley: Berkeley Linguistics Society. 


\section{Author's address}

\section{Mark Dingemanse}

Max Planck Institute for Psycholinguistics, Nijmegen

PB 301

6500 AH Nijmegen

Netherlands

mark.dingemanse@mpi.nl 